UDK: 624.012.4.059

DOI: https://doi.org/10.24867/14CG11Kozic

\title{
PROCENA STANJA I ENERGETSKA SANACIJA ZGRADE OSNOVNE ŠKOLE U KUPINOVU
}

\section{ASSESSMENT OF THE CONDITION AND ENERGY REHABILITATION OF THE PRIMARY SCHOOL BUILDING IN KUPINOVO}

\author{
Stefan Kozić, Fakultet tehničkih nauka, Novi Sad
}

\begin{abstract}
Oblast - GRAĐEVINARSTVO
Kratak sadržaj - Rad se sastoji iz dva dijela, teorijskog $i$ stručnog. U teorijskom dijelu su opisani glavni principi $i$ mehanizmi konstruisanja i funkcionisanja spušenih plafona. Detaljnije su opisana dva komercijalno korišćena sistema spušenih plafona: fiksirani $i$ modularni. U stručnom dijelu rada urađena je procjena stanja Osnovne škole Dušan Vukasović - Diogen u Kupinovu, zatim analiza energetskih performansi zgrade škole i ocena energetskog razreda. Predložene su mere za energetsku sanaciju zgrade $i$ ponovljen je proračun energetske efikasnosti. Dobijena je značajna energetska ušteda i zgrada je svrstana u energetski razred $C$.
\end{abstract}

Ključne riječi: Spušteni plafoni, procjena stanja, škola, energetska efikasnost, sanacija

\begin{abstract}
The paper consists of two parts, theoretical and professional. The theoretical part describes the main principles and mechanisms of construction and operation of suspended ceilings. 2 commercially used suspended ceiling systems are described in more detail: fixed and modular. In the professional part of the paper, an assessment of the condition of the Elementary School Dušan Vukasović - Diogenes in Kupinovo was made, then an analysis of the energy performance of the school building and an assessment of the energy class was done. Measures for energy rehabilitation of the building were proposed and the calculation of energy efficiency was repeated. The significant energy savings were obtained and the building was classified in energy class $C$.
\end{abstract}

Keywords: Suspended ceilings, assessment, school, energy efficiency, rehabilitation

\section{SPUŠTENI PLAFONI}

\subsection{Principi i podjela}

Spušteni plafoni se najčešće postavljaju u javnim objektima, a rjeđe i u porodičnim kućama. Njihova primarna svrha je skrivanje instalacionih vodova između plafona $\mathrm{i}$ spuštenog plafona, recimo, elektroinstalacija, instalacija za klimatizaciju ili ventilaciju, rasvjetu i slično.

Spušteni plafoni se koriste i na mjestima gdje je velika visina plafona pa se pomoću njih smanjuje visina plafona. Spušteni plafon, takođe, ima smisla kada je potrebna

\section{NAPOMENA:}

Ovaj rad proistekao je iz master rada čiji mentor je bila dr Mirjana Malešev, red. prof. dodatna termoizolacija međuetažne konstrukcije; osim toga, njime se poboljšava i međuetažna zvučna izolacija. Dakle, osim što je odlično funkcionalno riješenje sakrivanje instalacija koje kasnije brzo i lako mogu da se mijenjaju, dodaju i popravljaju bez građevinskih radova, spušten plafon je i požarna barijera - a istovremeno i stilsko, odnosno, estetsko riješenje za određen prostor. Postoje dva načina izvođenja spuštanog plafona [1]:

- Fiksirani (monolitni) spušteni plafon i

- Modularni (kasetirani) spušteni plafon.

Fiksirani plafon u odnosu na modularni plafon estetski je mnogo ljepši. Ima izgled kao da je izrađen od jednog komada (Slika1, levo). Potkonstrukcija fiksiranog plafona je dosta čvršća jer se ponaša kao cijelina što joj omogućava veću nosivost i tako može da izdrži veću debljinu termoizolacije od modularnog plafona.

Modularni plafon je urađen iz više cijelina i prilikom kvara instalacija (elektro ili mašinskih), koje se nalaze iznad plafona lakše se dolazi do instalacija i njihova popravka je jednostavnija što je i prednost modularnog plafona u odnosu na fiksirani plafon (slika 1, desno).



Slika 1. Tipovi spuštenih plafona, levo :fiksni, desno, modularni [2]

\section{PROCJENA STANJA OBJEKTA}

\subsection{Tehnički opis}

Objekat se nalazi u Kupinovu, adresa: Maršala Tita 1. Zgrada osnovnog obrazovanja je opšteg obrazovnog karaktera namjenjena djeci do 14 godina starosti. Osnovni karakter - klasičan vid škole sa fiskulturnom salom, učionicama, toaletima i kabinetima. Sagrađena je 1955. godine. Školska zgrada je spratnosti $\operatorname{Pr}+1$, a dio sa fiskulturnom salom je prizemni tip objekta. Bruto površina objekta je 1264,22 $\mathrm{m}^{2}$. Oba objekta zajedno formiraju u osnovi L oblik (Slike 2 i 3). Fiskulturna sala je dimenzija $24,21 \times 12,11 \mathrm{~m}$, a školska zgrada $45,17 \mathrm{x}$ $10,34 \mathrm{~m})$.

Objekat je fundiran na trakastim temeljima od pune opeke. Noseća konstrukcija objekta je zidana masivna 
konstrukcija sa nosećim zidanim zidovima u podužnom pravcu. Noseći zidovi su različite debljine. Zidani su od pune opeke standardnog formata i ukrućeni su AB horizontalnim serklažima i nosećim poprečnim zidovima u okviru stepenišnog trakta.

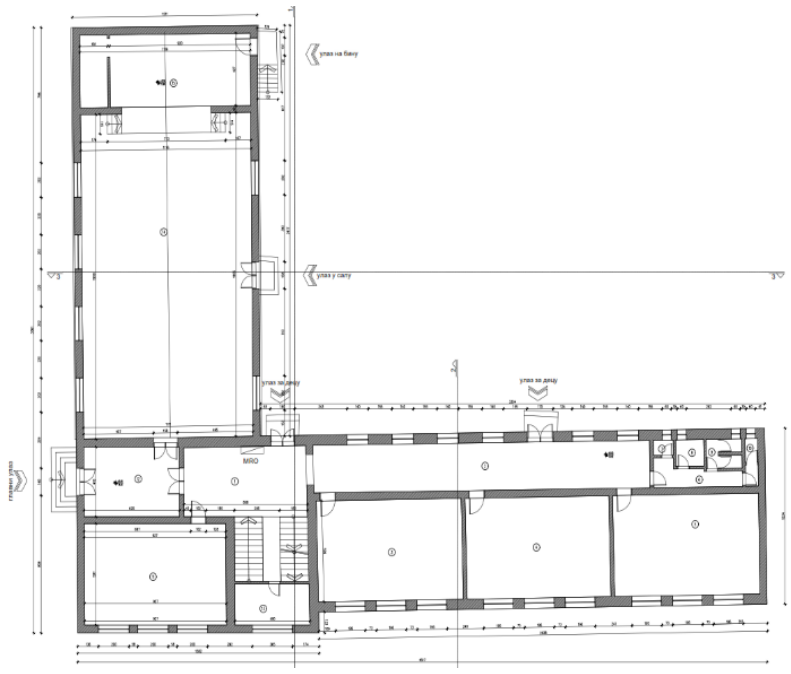

Slika 2. Osnova prizemlja

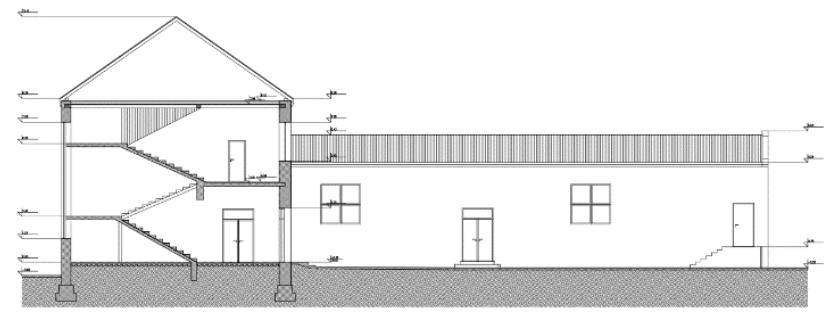

Slika 3. Presjek 1-1

Krovna konstrukcija nad školskim dijelom objekta je drvena (sistema jednostruka stolica), a krovni pokrivač je crijep.

Noseći zidovi u fiskulturnoj sali su fasadni podužni zidovi na koje se oslanja drvena krovna rešetka. $\mathrm{Na}$ drvenu krovnu rešetku je okačena potkonstrukcija spuštenog plafona od drveta. Krovni pokrivač je TR lim. Zidovi objekta su obostrano malterisani bez termoizolacije. Bina u fiskulturnoj sali je zidana punom opekom sa oblogom od drvenih elemenata.

\subsection{Vizuelni pregled objekta i analiza uočenih defekata i oštećenja}

Vizuelnim pregledom je ustanovljeno da se od glavnog projekta nije odstupalo, ali je vremenom došlo do promjene namjene nekih od prostorija, ali nije napravljena nijedna konstrukcijska izmjena.

Vizuelnim pregledom su obuhvaćeni: fasadni zidani zidovi sa spoljašnje i unutrašnje strane, unutrašnji zidovi, podna ploča u prizemlju, spušteni plafoni, drvena krovna konstrukcija i AB stepenište.

\subsection{1 Školska zgrada}

$\mathrm{Na}$ osnovu vizuelnog pregleda fasadnih zidanih zidova školskog dijela objekta sa spoljnje strane uočeni su sledeći defekti: 1) Neadekvatan izbor materijala za hidroizolaciju na sastavu sokle sa fasadnim zidom (hidroizolacija je odrađena sa premazom bitulita bez dodatnih elemenata i sintetičkog sloja) i oštećenja:
- trošnost materijala opeke na sokli objekta: krunjenje i otpadanje usled dejstva vlage, mraza i soli (slika 4,a),

- trošnost maltera: krunjenje i otpadanje maltera usled dejstva vlage, soli ili mraza na sjeverozapadnom i jugoistočnom dijelu fasadnog zida školskog dijela objekta i starenja materijala (Slika 4,b),

- mehanička oštećenja na fasadnim zidovima uslijed vađenja opeke i uslijed krunjenja slojeva zida za ispitivanje elemenata od kojih je sačinjen fasadni zid.
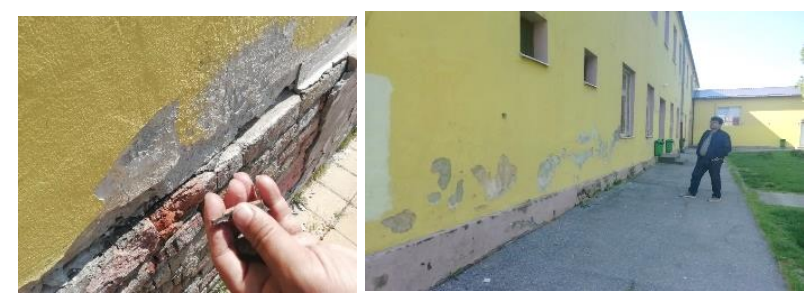

Slika 4. a) Trošan materijal, krunjenje elemenata opeke uslijed dejstva vlage, mraza, soli, oštećena i dotrajala hidroizolacija, b) Otpadanje,guljenje i ljuspanje maltera $i$ boje sa fasadnih zidova uslijed djelovanja kapilarne vlage

Vizuelnim pregledom se ustanovilo da je AB podna ploča u dobrom stanju, sa tim da su primjećena oštećenja na podnim oblogama: parket u lošem stanju, dotrajalost parkteta i pojava truleži u učionicama (Slika 5).

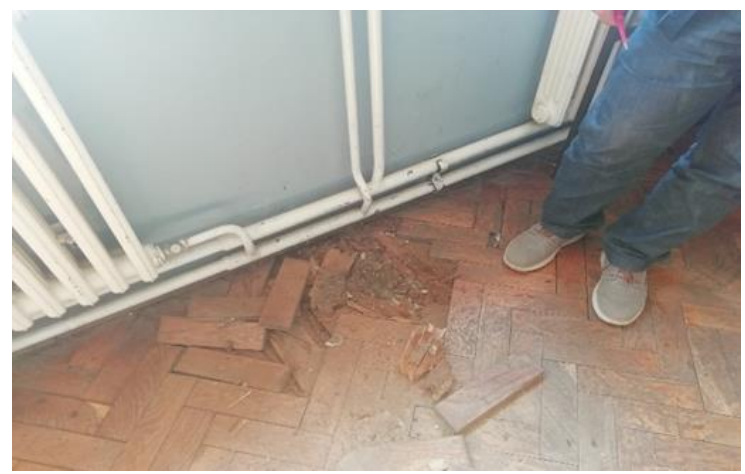

Slika 5. Parket u lošem stanju, trošnost i deterioracija materijala u učionicama, prizemlje

\subsubsection{Fiskulturna sala}

$\mathrm{Na}$ osnovu vizuelnog pregleda fasadnih zidanih zidova sa spoljašnje i unutrašnje strane fiskulturne, kao i na podnoj konstrukciji uočena su slična oštećenja i defekti kao na školskoj zgradi.

Spušteni plafon na fiskulturnoj sali je u lošem stanju. Zatečeni su samo neki manji dijelovi plafona na osnovu kojih se ustanovilo da se radi o drvenim oblogama (Slika 6).

\subsection{Zaključak o stanju objekta}

$\mathrm{Na}$ osnovu analize dostupne projektno-tehničke dokumentacije, detaljnog vizuelnog pregleda dostupnih dijelova elemenata konstrukcije, izvedeni su zaključci o stanju objekta po pitanju nosivosti, stabilnosti, trajnosti i upotrebljivosti (funkcionalnosti): 


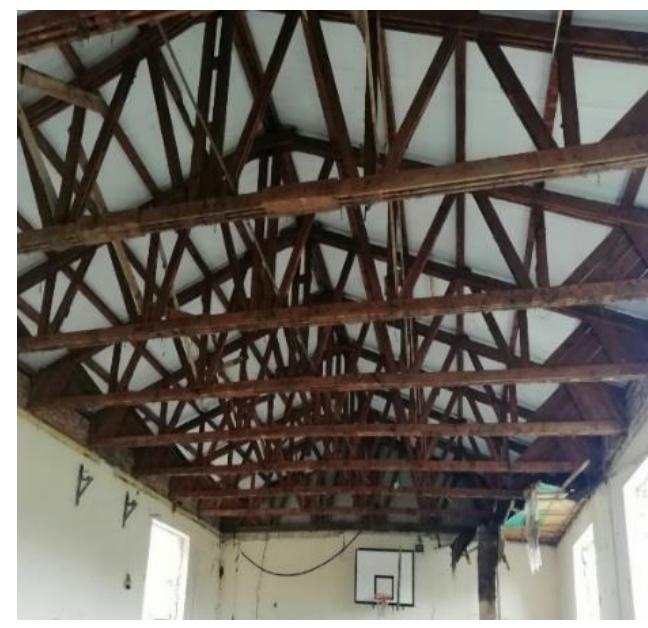

Slika 6. Dotrajala drvena krovna konstrukcija i ostaci spuštenog plafona

- Iako je objekat star više od 50 godina, zahvaljujući povremenom održavanju, još uvijek je u generalno dobrom stanju,

- Na objektu nisu registrovana ozbiljnija oštećenja materijala od koga je izvedena osnovna noseća konstrukcija,

- Posmatrajući konstrukciju u cjelini, može se zaključiti da nosivost i stabilnost objekta nisu ugroženi, ali trajnost pojedinih elemenata i funkcionalnost objekta su djelimično narušene.

\section{ENERGETSKA EFIKASNOST - POSTOJEĆE STANJE}

Proračun je u svemu sproveden prema važećem Pravilniku o energetskoj efikasnosti zgrada. Sklopovi termičkog omotača školske zgrde i fiskulturne sale su, najprije, podeljeni na transparentne i netransparentne $u$ zavisnosti od slojeva i položaja ovih elemenata.

Za svaku od pozicija termičkog omotača urađen je proračun građevinske fizike, koji podrazumjeva određivanje koeficijenata prolaza toplote, a za netransparentne sklopove određeni su i raspored temperatura, minimalna otpornost sklopa, difuzija vodene pare i parametri ljetnje stabilnosti.

Svi analizirani sklopovi su imali veći koeficijent prolaza toplote od pravilnikom propisane vrijednosti.

Nakon izvršenog proračuna za svaku poziciju ponaosob, pristupilo se proračunu toplotnih gubitaka i dobitaka zgrade kao cjeline, u cilju određivanja potrebne energije za obezbjeđenje osnovnih uslova toplotnog komfora. Proračunati gubici toplote prikazani su na slici 7 .

$\mathrm{Na}$ kraju, proračunata je ukupna potrebna energija za grijanje škole na godišnjem nivou, na osnovu koje je škola svrstana u energetski razred F.

\begin{tabular}{|c|}
\hline$Q_{H, n d}=196912 \mathrm{kWh} / \mathrm{a}$ \\
\hline$q_{H, n d}=188 \mathrm{kWh} / \mathrm{m}^{2} a$ \\
\hline$Q_{H, n d, r e l}=250 \%$ \\
\hline Razred: $\mathbf{F}$ \\
\hline
\end{tabular}

- Transmisioni gubici kroz netransparentni površine

- Transmisioni gubici kroz transparentne površine

- Linijski gubici

- Ventilacioni gubici

\section{2,86}

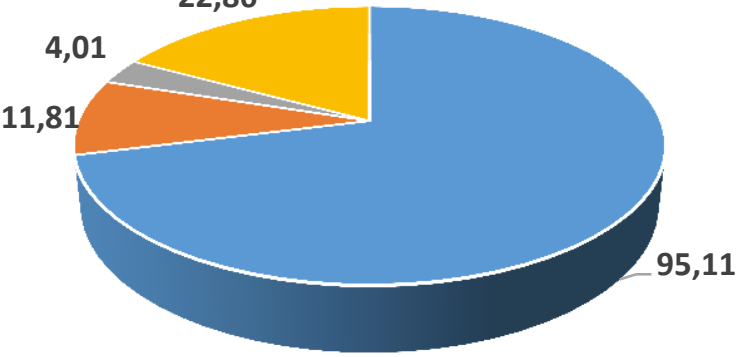

Slika 7. Gubici toplote, postojeće stanje

\section{ENERGETSKA SANACIJA I ENERGETSKI RAZRED SANIRANOG OBJEKTA}

Prilikom proračuna provođenja toplote zaključeno je da svi analizirani sklopovi termičkog omotača zgrade (fasadni zidovi, zid ka negrijanom prostoru, ploča prizemlja, plafonska konstrukcija ka negrijanom prostoru, međuspratna konstrukcija, PVC prozori i vrata) ne zadovoljavaju uslov maksimalnog dozvoljenog koeficijenta prolaza toplote. Za unapređenje energetske efikasnosti objekta predložene su sledeće mjere:

- Spoljnji zidovi su popravljeni Alucobond ventilisanom fasadom, koja u isto vrijeme bolje toplotno izoluje objekat zbog ugrađivanja sloja kamene vune, a i štiti objekat od atmosferilija i time mu povećavajući trajnost (slika 8). Takođe uklanja i glavni uzročnik oštećenja u objektu - atmosfersku vlagu.

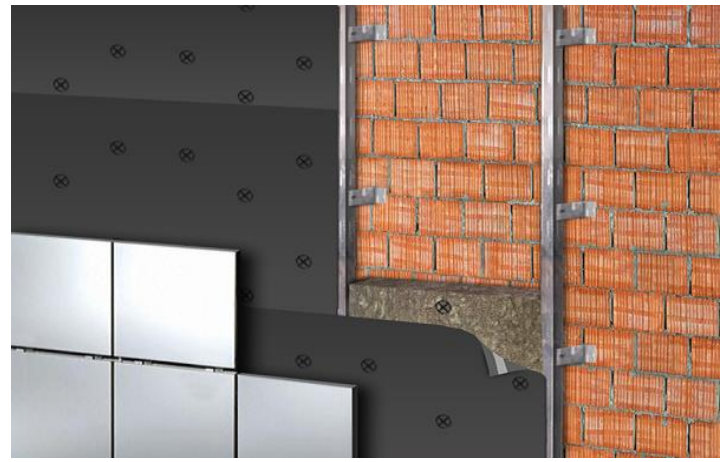

Slika 8. Izgled ventilisane fasade (potkonstrukcija, kamena vuna, ploče od Alukobonda)

- U okviru konstrukcije poda, radi poboljšanja energetske efikasnosti, predloženo je dodavanje ekspandiranog polistirena debljine $10 \mathrm{~cm} \mathrm{u}$ sklop. Pošto se radi o podnoj ploči, zbog obezbeđenja građevinskih visina unutrašnjih i spoljašnjih vrata, prozora i pregrada, potrebno je ukloniti postojeću podnu konstrukciju i napraviti novu sa potkopavanjem od $10 \mathrm{~cm}$ kako bi se u sklop ubacio sloj ekspandiranog polistirena debljine $10 \mathrm{~cm}$.

- U okviru međuspratne i plafonske konstrukcije fiskulturne sale, izveden je sistem fiksiranog spuštenog plafona, iznad koga je postavljena termička izolacija od staklene vune (slika 9), čime je poboljšana energetska efikasnost objekta. 


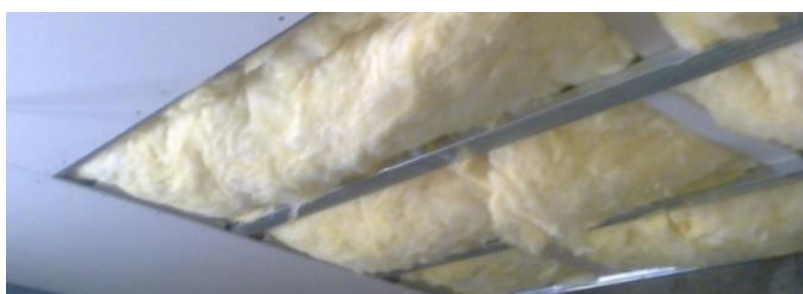

Slika 9. Spušteni plafon: Postavljanje staklene vune $i$ gipskarton ploča na potkonstrukciju

Pri proračunu energetske efikasnosti spoljašnja PVC stolarija nije zadovoljila maksimalni dozvoljeni koeficijent prolaza toplote, međutim, odstupanja od dozvoljenog koeficijenta prolaska toplote su mala, pa se pri ovom unapređenju energetske efikasnosti objekta neće mjenjati spoljnja stolarija.

Nakon ponovljenog proračuna energetske efikasnosti na saniranom objektu (Slika 10), on je svrstan u energetski razred $\mathrm{C}$.

\begin{tabular}{|c|}
\hline$Q_{H, n d}=63006,515 \mathrm{kWh} / \mathrm{a}$ \\
\hline$q_{H, n d}=60,20 \mathrm{kWh} / \mathrm{m}^{2} a$ \\
\hline$Q_{H, n d, r e l}=80 \%$ \\
\hline Razred: $\mathbf{C}$ \\
\hline
\end{tabular}

- Transmisioni gubici kroz netransparentni površine

- Transmisioni gubici kroz transparentne površine

- Linijski gubici

- Ventilacioni gubici

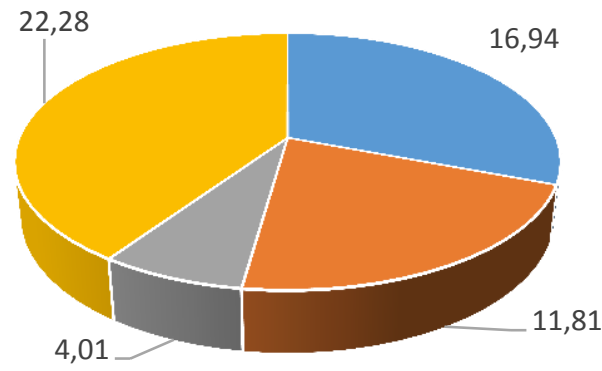

Slika 10 - Gubici toplote za energetski sanirani objekat

Sve ostale elemente konstrukcije, koji nisu obuhvaćeni proračunom energetske efikasnosti, je potrebno sanirati odgovarajućim sanacionim rješenjima.

\section{ZAKLJUČAK}

U stručnom dijelu rada izvršena je procjena stanja osnovne škole Dušan Vukasović - Diogen u Kupinovu, analiza energetskih performansi elemenata konstrukcije objekta i energetska sanacija istog. Iako je objekat star više od 50 godina, zahvaljujući povremenom održavanju, još uvijek je u generalno dobrom stanju.
Posmatrajući konstrukciju u cjelini, može se zaključiti da nosivost i stabilnost objekta nisu ugroženi, ali trajnost pojedinih elemenata i funkcionalnost objekta su djelimično narušene.

Proračun energetske efikasnosti je obavljen prema važećem Pravilniku o energetskoj efikasnosti zgrada, „Službeni glasnik RS“ br. 061/2011, objavljenim 19.08.2011. godine. Objekat je kategorizovan u energetski razred $\mathrm{F}$, što predstavlja relativno nisku klasu energetske efikasnosti. Kako bi se u isto vrijeme povećala trajnost objekta, ali i smanjila količina energije potrebne za zagrijavanje, popravljene su karakteristike određenih elemenata objekta:

- Spoljnji zidovi su popravljeni Alucobond ventilisanom fasadom, koja u isto vreme bolje toplotno izoluje objekat, a i štiti objekat od atmosferilija, time mu povećavajući trajnost.

- U okviru konstrukcije poda, promenjen je sklop umetanjem dodatnog sloja - eskpandirani polistiren,

- U okviru međuspratne i plafonske konstrukcije fiskulturne sale, izveden je sistem fiksiranog spuštenog plafona, sa odgovarajućom debljinom sloja termoizolacije od staklene vune.

Nakon ponovljenog proračuna energetske efikasnosti na saniranom objektu, on je svrstan $\mathrm{u}$ energetski razred $\mathrm{C}$. Budući da se energetska sanacija jednog objekta smatra uspješnom ako se energetski razred podigne za jedan, ova sanacija se smatra više nego uspješnom.

\section{LITERATURA}

[1] Gips u enterijeru - (politika.rs), preuzeto: 23.06.2021.

[2] Spušteni plafoni: knauf ili armstrong (daibau.rs), preuzeto: 23.06.2021.

[3] Kako se pravilno spuštaju plafoni - montaža i cena (video) (gradnja.rs), preuzeto: 23.06.2021.

[4] Projekat postojećeg stanja osnovne škole Dušan Vukasović - Diogen u Kupinovu.

[5] Pravilnik o energetskoj efikasnosti zgrade „Službeni glasnik RS“ br. 61/2011, objavljen 19.08.2011. godine.

\section{Kratka biografija:}

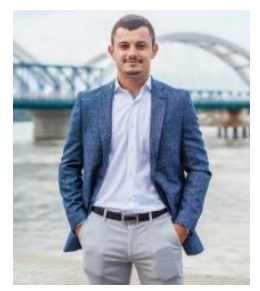

Stefan Kozić rođen je u Trebinju 1995.god. Master rad na Fakultetu tehničkih nauka iz oblasti Građevinarstvo - Konstrukcije: Oštećenja i sanacija zidanih konstrukcija i Energetska efikasnost, odbranio je 2021.god kontakt: stefankozic0@gmail.com 